\title{
VISIONARY SCENARIOS FOR PLANNING OF ENERGY- EFFICIENT BUILDINGS AND NEIGHBOURHOODS
}

\author{
KRZYSZTOF KLOBUT ${ }^{1}$, MARI HUKKALAINEN \& TARJA MÄKELÄINEN \\ VTT Technical Research Centre of Finland Ltd., Finland.
}

\begin{abstract}
Holistic approach is required to achieve energy-efficient design of buildings that are integrated to the neighbourhood energy systems. This paper presents selected phases of the design process in the form of visionary scenarios involving new technologies, numerical services and business models. Evaluation of potential impacts and the needed progress beyond the state of the art, as well as user requirements for the visionary stories are identified. As an example, visionary scenario for neighbourhood energy balancing in building design is presented in detail to demonstrate the usefulness of conducting energy analysis on a higher level, beyond a single building. The practical value of utilising the district energy analysis depends strongly on how the results are communicated to the relevant stakeholders and how they are utilised in the urban planning and related decision making. The district energy analyses, when performed iteratively during the progressing planning process, reveal to urban planners the effects of their decision choices. They could also provide sufficient base information for the decision making about the land use and urban development on the city level. To account for future changes that affect the energy system but are not handled properly in today's design process, an eAdaptability concept is introduced.

Keywords: design, energy-efficient buildings, future scenarios, holistic, neighbourhoods.
\end{abstract}

\section{INTRODUCTION}

World is currently facing a challenge of global warming. Simultaneously, rapidly increasing urbanisation appears as one of the megatrends, with the role of built environment becoming more and more important. In the context of improving global sustainability, the building sector has been recognized as a key sector of the economy. Planning of cities and districts plays an important role here, as design decisions have an important effect on the sustainability at the local level. The topic of energy efficiency in urban planning is very broad and it is a true challenge to include all different aspects into a holistic approach that is needed in this context, while at the same time balancing with other design targets. Since combining different disciplines into a holistic approach for energy-efficient design is desirable, it calls for guidelines, easy-to-use tools and structured planning processes that bring different disciplines together into a common framework to assist city planners in making the informed decisions. For stakeholders it is important to understand what decisions are made at which stage of the planning process. It also is important for decision makers to realise the impact of their decisions, because already early stage decisions may be irreversible or very costly to modify in the later stages of the process.

The work described in this paper was carried out in the frames of international collaboration effort called Design4Energy project (D4E), which focuses on innovative and integrated evolutionary design methodology for energy-efficient buildings, which are flexibly connected with the neighbourhood energy system [1]. The purpose of this part of the study was to improve the understanding of holistic, evolutionary and energy-efficient planning and design of buildings and neighbourhoods. Especially, this paper focuses on developing future

\footnotetext{
${ }^{1}$ ORCID: http://orcid.org/0000-0002-5892-7066
} 
scenarios for integrating buildings with neighbourhood energy systems as efficiently as possible. These kinds of considerations emerge from the implementation efforts of European Union's nearly zero energy building targets [2]. The scenarios will consider foreseeable new technologies, numerical information services and business models.

The presented work creates a span between the earlier developed roadmap for energyefficient buildings [3], through the visions of the future energy-efficient buildings and neighbourhoods from the ICT (Information and Communication Technologies) roadmap for energy-efficient neighbourhoods [4], until the energy matching framework for energy positive neighbourhoods [5]. The envisaged energy system scenarios are developed further in D4E project using the Integrated Design and Delivery Solutions (IDDS) framework [6]. The IDDS formalism enables the iteration of future design solutions and team level communication, with the support from an advanced service platform that includes a BIM server. Collaborative environments developed in the D4E can support multi-functional team in designing energy-efficient building with a consideration of their neighbourhoods [7].

The key objectives for the building design methodology have been defined in the D4E project to be: 1) holistic; 2) evolutionary, 3) adaptable for designing approaches and methods; 4) multi-disciplinary design practice in integrated processes, 5) providing an information service for decision-making, 6) value-adding \& orientated towards energy-efficiency. In this project, the methodology is considered as a set of methods, rules and principles employed in welldefined procedures for designing cost effective energy-efficient buildings and their assessment in a neighbourhood context [8]. The main principle for the energy design is firstly to minimize the energy demand, and secondly to design the adequate energy mix (including heat, electricity, and cooling). Passive energy design solutions are encouraged for the design team.

\section{METHODOLOGY FOR DEVELOPING FUTURE SCENARIOS}

A visionary story reaches out into the future. It describes an exemplary sequence of actions and tasks by stakeholders using models, methods, and tools. Visionary scenarios extend beyond the state of the art of design, planning, ICT, business processes and models. The presented scenarios are examples and may not cover all needed ways of using the tools.

The visionary stories were developed using both Top-down and Bottom-up approaches. At first, the working process started by developing the vision and anticipated developments related to energy-efficient design. This was followed by the visionary scenario development, consisting of the following steps:

1. Defining the scenario topics,

2. Drafting the trends/visions for each scenario,

3. Visionary scenario descriptions,

4. Finalising envisioned visions,

5. Analysing the user requirements in scenarios, including innovations related to ICT, business models and energy efficiency.

Visionary scenarios were developed in collaboration among the D4E project partners as an iterative process, with partners reviewing and improving others' contributions based on their own expertise fields and practical knowledge [8].

\section{VISIONARY SCENARIOS AND RELATED USER REQUIREMENTS}

The vision for neighbourhood planning highlights the role of 'energy efficiency at the heart of holistic planning of new and existing neighbourhoods', and underlines the availability of 
relevant data and ICT tools to support holistic decision making in neighbourhood [4]. Relevant, timely and linked data accessible via open platforms supports transparency and close cooperation in the planning and management of neighbourhoods, involving a range of partners in the realisation of energy-efficient neighbourhoods from public, private and civil society sectors. The aim is that neighbourhood planning incorporates all aspects of energy conservation relating to the built environment and associated socio-economic activities, such as working, commuting as well as access to services and leisure. ICT systems enable robust planning decisions based on optimising energy efficiency and economic performance. The purpose of ICT in this context is to provide access to methodologies, tools and data that facilitate accurate simulations of a neighbourhood's energy characteristics based on interdependencies as part of the wider ecosystem. As part of the on-going maintenance and management of energy-efficient neighbourhoods, a range of energy services will offer ICT-enabled automated responses to conserve energy in relation to utilities, transport and passive energy design. Furthermore, ICT plays a key role in integrated and real time optimised energy systems planning and operation, and making future predictions of the energy performance and its costs. In addition to new technologies, new business concepts and economic imperatives are needed. Incentives and taxation therefore underpin the realisation of the vision. The details of the roadmap are shown in Fig. 1.

Expected impacts include that decision makers will have tools giving them a clear understanding of different energy system alternatives and their impacts. Location-specific data is linked and accessible, openly available and processed by easy to use applications. As a result, meaningful information is more readily available in accessible formats for different users and

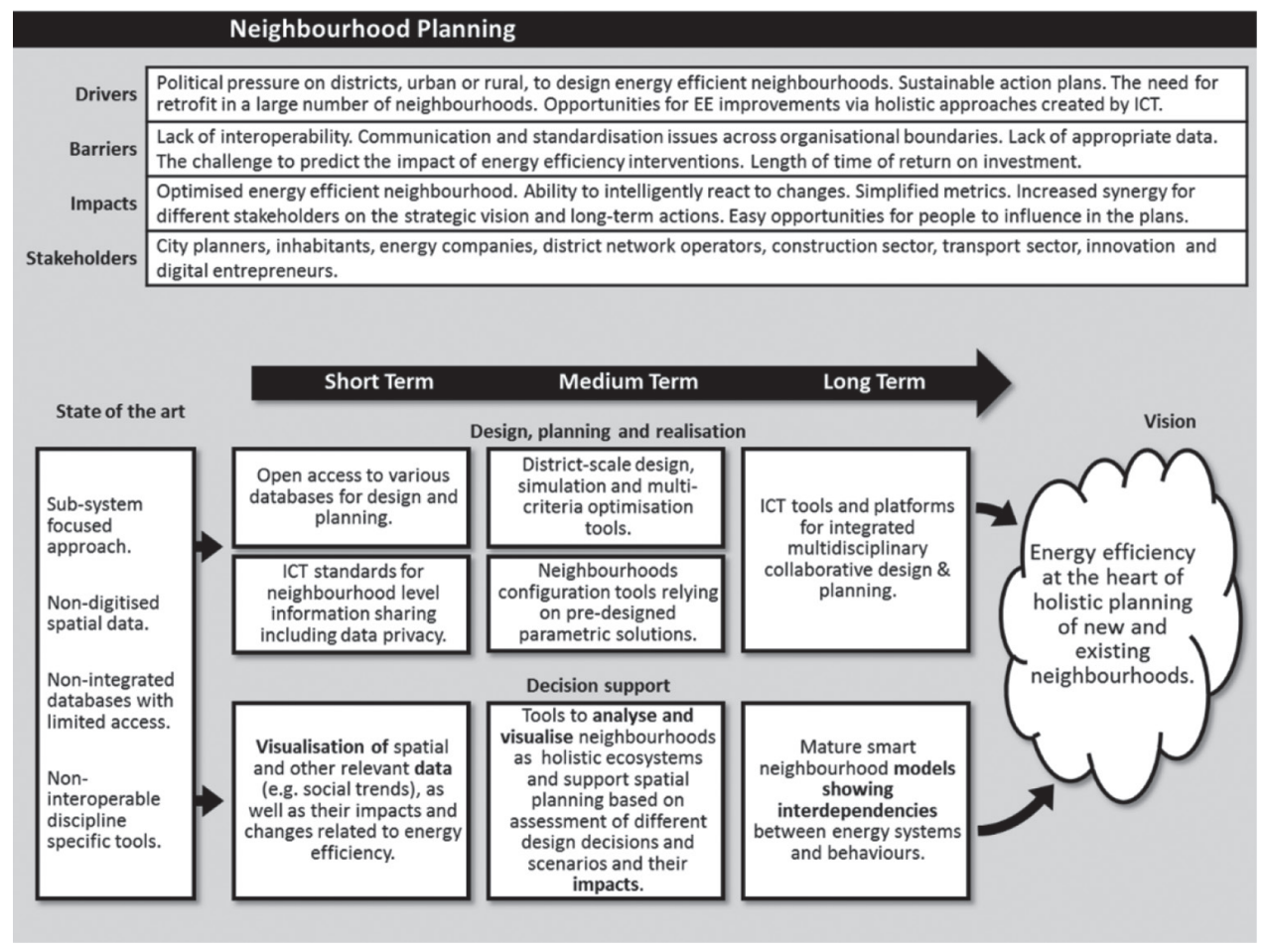

Figure 1: Roadmap for the neighbourhood planning [4]. 
stakeholders such as consumers, utilities, and energy service companies. Energy efficiency improves through increased understanding and synergies, underpinned by energy-efficiency driven business models.

Whilst the above vision is described from the neighbourhood planning perspective, it looks towards the future from the building design point of view for design teams. In the D4E project further progress was made and a total of 10 visionary scenario topics were identified and developed [8]:

1. Collaborative planning of neighbourhood energy systems;

2. Neighbourhood energy balancing in building design;

3. Energy matching design;

4. Integrated building design management;

5. Decision support for design;

6. Passive architectural design solutions;

7. Building performance management;

8. ICT and interoperability possibilities in design collaboration;

9. Design with the micro climate and environmental point of view;

10. Stimulating user interaction and behavioural changes of inhabitants.

The first from the above-listed visionary scenarios was discussed in our related publication [9]. In the following section here, we briefly address the second visionary story about neighbourhood energy balancing in building design.

\section{NEIGHBOURHOOD ENERGY BALANCING IN BUILDING DESIGN}

This scenario elaborates on balancing neighbourhood energy system, and how it is related to the building design through integrated building modelling and simulation throughout the entire life-cycle. The scenario description targets to show how advanced simulation and modelling techniques could be used to improve the energy design practices. In addition, this scenario gives an example on the different stages of the community design from the energy system viewpoint. Typically, the community life cycle is long and estimating the energy performance of the buildings and network is challenging at the various phases of the design process [8].

\subsection{The visionary story for neighbourhood energy balancing in building design}

An energy designer works together with the building architect and the building design team. His main responsibility is to solve energy related design challenges according to the clients' needs. As a first thing he studies the contract documents, typically including a set of main criteria for the performance based design process, categorised in three levels: project, process and product. Criteria for energy optimisation are: life cycle cost $\left(€ / \mathrm{m}^{2}\right)$, share of renewable energy (\%), energy self-sufficiency (\%), primary energy need for electricity, heat and cooling $\left(\mathrm{kWh} / \mathrm{m}^{2}\right)$, and energy use reliability, including the reliability of local grid $(\%)$. In essence, energy designer's assignment is to prepare a proposal for the target setting. For this, he needs to run energy calculations and estimate target values for each of the criteria and conduct feasibility studies [9].

It is a demanding task to set the target value for life cycle costs because they will depend on different design options and solutions of the design team done already in the concept design phase. Feasibility studies interesting from the investor perspective could be: 
1) business as usual (BAU), 2) energy efficient, and 3) highly energy efficient, which includes the heat trading with the local district heating grid.

Energy planning tool should be able to import a sketch design from Building Information Modelling (BIM) server and a city plan information from the city model. The process should allow for a RFI (request for information) exchange with an architect through a collaborative working environment. During the BIM-import, the tool asks for the conceptual definition of the building to be modelled, and about the weather station nearest to the construction site. At this stage energy simulation of different design options can begin [9].

The hourly price of energy products (district heating, electricity and district cooling) and the pricing of the bought and sold energy will still be needed for life cycle cost calculation in the BAU case. Then, the improved energy-efficiency option can be simulated, with heat trading business model, including on-site RES production (renewable energy sources), e.g. with solar heat collectors. The design of the third option for highly energy-efficient will include the heat balancing with the local district heating grid.

As a result of the process the client gets: 1) target value set for the criteria of energy efficiency, and 2) preliminary results of building energy simulation and planning feasibility studies with using advanced energy balancing techniques in the building. These can guide the client and the design team on further steps to find the best possible energy-efficient design.

\subsection{Expected impacts and the main stakeholders}

Energy matching aims to balance the energy supply from local renewable sources with the energy demand of a neighbourhood. This will include maximising energy efficiency and minimising peak power demand, while maximising the local renewable energy supply and the management of energy storage. The energy demand and its potential flexibility (shifting of times of use, etc.) can be utilised for energy matching with the available local renewable energy sources, and/or with the energy tariff levels from energy markets. New potential indicators useful in this context are presented in work [10].

The neighbourhood energy balancing related to the building design is expected to improve the matching of energy supply and demand. This can lead to reduced peak power loads, and as a consequence, it can contribute to reducing emissions from energy production, because peak power is typically produced from fossil fuels with high emissions. Furthermore, energy balancing helps to optimise the energy use and minimise the energy costs of the building, and increase the share of local and on-site renewable energy supply [8].

Neighbourhood level of energy balancing could take place within a heat market that could work similarly to a liberated electric market in Nordic countries, with the exception that the heat market can be only realised within a local district heating or gas network. Such an open heating energy market would require the network operators to take care of the temperatures, pressures and hydraulic balance of the energy network. A balance-sheet operator is also needed to coordinate the heat contracts between producers and customers as well as to take care of reserve capacity, spot and future markets and billing. Energy producer supplies thermal energy or gas through the energy network for its customers. Network operator is responsible for the district heating or gas network. The local network service must be separated from production, but the network operator can also make contracts both with producers and with customers. Balance sheet operator coordinates the whole district heating/cooling system and keeps up the thermal load and energy balance sheet within the network. Consumers are customers, who buy the energy and pay the bills and whose role in the network is a subject to conditions of technical and regulatory nature [8]. 


\subsection{Progress beyond the state of the art}

Currently energy simulations are dilatory in their nature and are performed too late in the design process to adequately effect on the project level decision making. Tools do not yet exist for easily defining thermo-hydraulic model of the energy trading as a whole. If modelling is used for the district heating network, the models are unconnected. Today, the energy companies use stand-alone network models to solve some initial or critical stages of network flows, mainly design points. The network design practice is based more or less on the rules of thumbs. The building simulations are at the current practice independent and are mainly used to analyse the indoor climate and energy consumption of buildings. Also the renewable (wind, solar, geothermal) energy production models are still often separate ones.

The aim of the D4E project was to create new methodology and tools to move from this current position to allow design teams to take a holistic view in designing energy-efficient buildings within the context of neighbourhood.

D4E aim and vision was to create a fully interoperable technology platform integrated with a range of information sources, simulation and design exploration tools that can allow design teams to work together to optimise the design or renovation of buildings in neighbourhoods according to the objectives (e.g. energy efficiency, minimise the use of non-local energy at district level, minimise cost to consumers), and taking into account existing constraints (network capacity, production availability and costs, market energy prices, etc.). It will allow design teams to explore alternative design possibilities that take into account neighbourhood characteristics (social, environmental, economical), energy trading options, energy usage patterns derived from maintenance and operation data, energy related parameters (weather patterns, external lighting, temperature, airflow, etc.) and to select the most energy-efficient solutions without compromising other aspects of the building such as aesthetic, structural and acoustic performance. Easy to use configuration tools relying on pre-designed parametric solutions for the design or renovation of neighbourhood buildings will play a key role in this platform. By using the D4E platform the designers will be able to conduct whole lifecycle assessment of energy performance and cost implications of a building [7].

\section{ANTICIPATED FUTURE CHANGES RELATED TO ENERGY DESIGN}

When studying and developing methodologies for building energy design, it is necessary to anticipate also possible future changes related to energy design. The possible changes can be related, e.g. to: how the building itself is operated and what is required from it; how the neighbourhood energy systems will change, how policies and legal frameworks will develop, what kind of new technologies will be available, how the pricing levels will develop, and other external changes in the environment.

The needs and requirements for the operation and the use of buildings can be increasingly common in the future, among others due to targets to increase the efficiency of using building spaces and changing user expectations. For example, a design requirement can be that the use of buildings and spaces should be flexible in the long term, and possible to be changes easily without heavy renovations, such as changing of the apartment sizes, or changing the type of service or office spaces. For building energy system this means that it should be easily adaptable to different usage of spaces. Alternative future change is that buildings' users can have increasing expectations in the future, e.g. for comfortable indoor air conditions, more individual control of conformance and energy performance. The energy use of buildings will change also, e.g. if users adopts electrical cars and want to charge it in the building premises. Furthermore, the ownership and maintenance models can change in the future. 
Outside of the building, the energy system changes in the local area, services and neighbourhood can also create a need for future changes in building energy design. Especially this is related energy supply and used energy sources, e.g. if changes would happen in the district heating, cooling and gas networks. It could be wise to reserve a possibility for easy installation of, e.g. solar panels or collectors for the building energy system. Additional factor here is the changes in the energy costs. For example, if energy prices would rise significantly, or if real-time electricity price tariffs would be adopted, it would be beneficial that the building energy management system would allow for taking the full advantage of possible energy bill savings by managing the energy use, and/or balancing the energy demand to the fluctuating renewable energy availability.

On national and European level, legal and policy framework developments also create potential future changes. For example, they can effect to financing arrangements, tax levels, and energy subsidies. New building regulations can also change the building design boundaries, e.g. in case future building renovations.

Naturally, also up-coming technology developments can require future changes. For example, building energy solutions will develop all the time, and they should be considered when doing building renovations. Also users can start to use different kind of new technologies by themselves, which can effect to the building energy use directly. For example, if people start to use new electrical equipment, they usually increase electricity use and cause heat losses coming to the building spaces, which might require adapting of building heating and ventilation systems to avoid overheating of spaces.

Additional external changes can be caused from changes in the environment. For example, due to climate change, extreme weather conditions may occur more often and more radically, which can require extra design alternative consideration for example related to rain water management in the building site. Optionally, changes in local services and transport and logistic options can also change how people are using the building spaces and what kind of requirements they have for them.

\subsection{What-if situations for building energy design}

What-if situations are examples of possible future changes that could be taken into account in the adaptability design. Change scenarios are taking care during design process with help of what if -analyses. If there are many possible solutions to adapt to change situations, their performance should be assessed and the best alternative selected. Some typical future changes in the scope of D4E are described as follows (and summarised in Fig. 2):

1. Changes of energy pricing:

- Price of energy (global, national, regional and local development).

- Volatility due to high penetration of RES in the neighbourhood.

- An example of what-if situation: Energy price is $20 \%$ higher, how does the energy system reflect the changed circumstances?

- Possibility to add energy storage and its optimal capacity design: one way to cope with increasingly fluctuating real-time energy prices (avoiding of expensive peak hours). More fluctuation in electricity pricing (among others due to increasing the share of RES), which can cause significant fluctuation in the real time electricity pricing and cause more expensive electricity price tariffs at some times.

- Long-term future changes (over 50 years) in the energy markets may require radical modifications of the technical building services and building structure. 


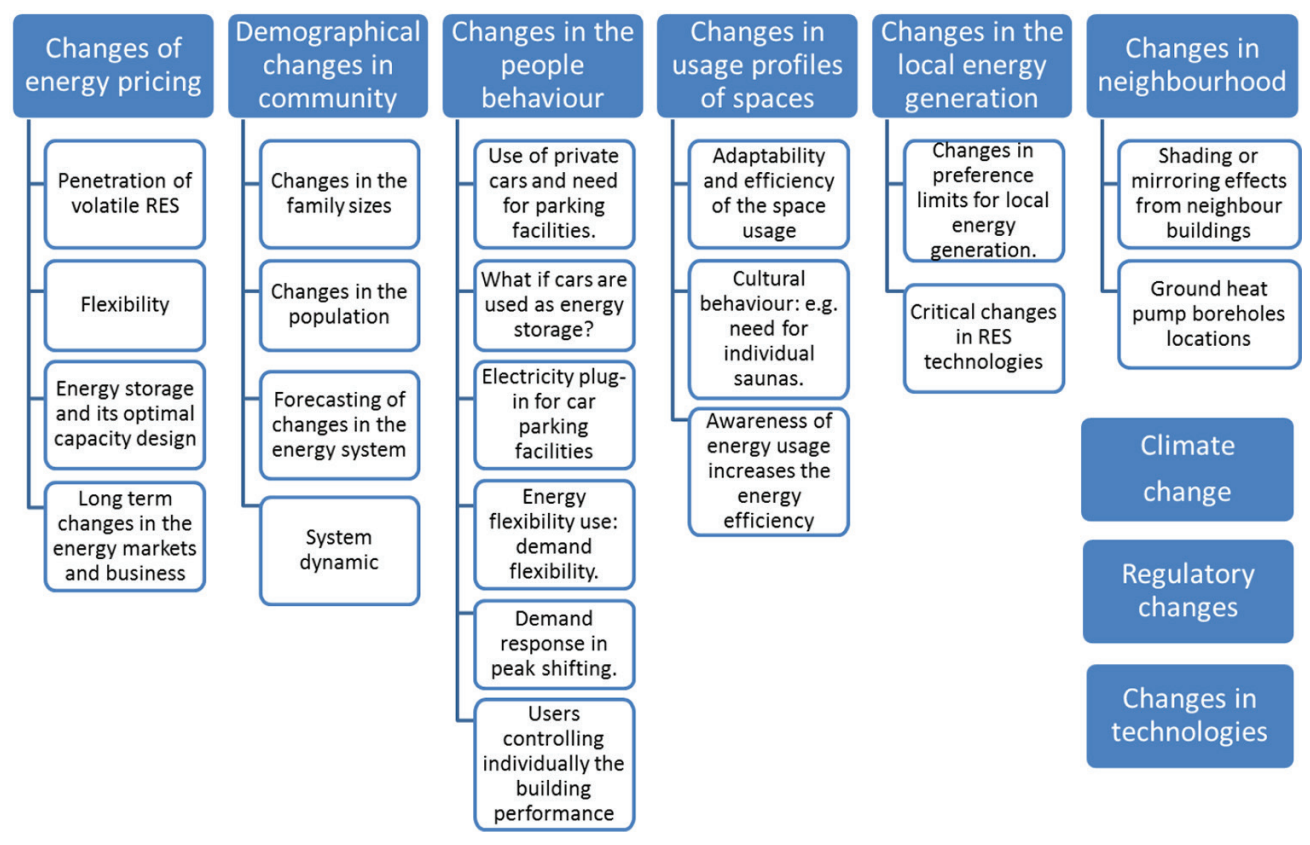

Figure 2: Examples of future changes and what-if situations in building energy design.

2. Demographical changes in community:

- Changes in the family sizes, e.g. increasing demand for smaller apartments.

- Changes in the population; to be forecasted with:

- urban planning tools and service network analysis,

- forecasting of district energy system changes with, e.g. ATLAS tool developed in IDEAS project [11].

- forecasting the need for public service spaces (e.g. schools, day care centres).

o one potential method: system dynamics.

- What if: the neighbourhood is under development within the next 20 years - what would be optimal layout and size of apartments in a building in order to maximise the profit?

3. Changes in the people behaviour:

- Changes in the people preferences: e.g. ownership of cars: how many people need private car parking facilities? Transportation and use of private cars - parking facilities. Car parking facilities are expensive. Effects to the space demand of the bicycle storages.

- What if batteries in cars are increasingly used as energy storage in the future? Already now electricity plug-in spots are available in private car parking places.

- Energy flexibility utilisation: demand flexibility.

- Demand response to achieve peak shifting.

- Developments in possibility that users can control individually the building performance, e.g. temperature, ventilation, and cooling.

4. Changes in usage profiles of spaces: possibility to adapt the space usage, e.g. from office to residential building.

- Adaptability is achieved by design strategies like flexible routes of HVAC-systems or spatial buffers/space allocation. 
- Changes in cultural behaviour (e.g. in Finland one sauna for hire to inhabitants in an apartment building instead of private saunas in each apartment).

- Different user preferences concerning flexibility, e.g. early adapters.

- Awareness of energy usage among residents can increase the efficiency of energy use, e.g. through the comparison of individual residents' consumption to the average energy consumption in the same or similar building, district and city; and showing of real-time energy usage. This could reduce the energy demand.

- What-if analysis question: what mix of space usage could provide the best energy matching option (especially in large building complexes and in neighbourhood)?

- How building space use efficiency could be improved?

5. Changes in the local energy generation:

- Changes in surplus amount.

- Changes in preference limits for local energy generation. Energy tariff strategies can be either dynamic or fixed price level.

- Critical changes in local RES technologies with significantly reduced costs can change the local energy markets and supply.

6. Changes in neighbourhood:

- Other building types in the neighbourhood.

- What if there will be new buildings (or other shading), which reduces on-site solar production in the existing building?

- Shading or mirroring effects from neighbour buildings, e.g. mirroring effect from the nearby building can increase the need for cooling in an office building.

- If new ground heat pump boreholes will be installed nearby existing heat pumps' boreholes, potential temperature changes to the existing system, and hence, the coefficiency of the performance of the heat pumps can reduce.

\subsection{The eAdaptability concept}

Future changes that might affect the energy system are not been handled properly in today's design process. This can be improved by adaptable design, defined as a design characteristic comprising spatial, structural, and service strategies which allow the physical artefact (building) a level of malleability in response to changing operational parameters over time. We consider here eAdaptability energy-wise.

The strategies for adaptability have been studied. For example, Adaptable Futures Group at Loughborough University have developed broader approaches and defines that 'Adaptable is the capacity for a building to accommodate effectively the evolving demands of its context, thus maximizing its value through life' [12].

eAdaptability could be regarded as a qualitative indicator and its' value levels can be drafted based on potential changes during the building lifetime. To implement management of future changes with help of eAdaptability indicator, also a novel working session needs to be developed for design process e.g. called 'Adaptability analysis'.

Ideas for further development of this working session as a process:

- Integrated energy design know-how is needed from all design domains.

- Adaptability design solutions are discussed in working session and co-design supported by a working agenda team meetings. It's important for the design team to know that the solutions are going to support better flexibility or adaptability, and to what extent.

- General value level definitions are set, and assessed, in different phases of design. 
- Design Advisory can be developed.

- Spatial design in functional blocs is suggested. By dividing all spaces of the designed building to stable parts and changing parts, it is easier to consider adaptability levels. This is also one of the principals of open building.

- Scenario for technical development: Adaptability analysis could be supported by collaborative working templates based on the content of the future change blocks with related what-if questions.

\section{DISCUSSION AND CONCLUSIONS}

Many energy and environmentally related goals aim towards improving energy efficiency, reducing emissions and increasing renewable energy share. These challenges are being addressed in a number of decisions - and choices between alternative plans - by planners and municipal decision makers, which often have a major impact on energy efficiency and emissions at local level. Energy-efficient district planning can be supported by examining the energy demand at district level and comparing the environmental impacts of alternative energy solutions.

In this paper, we explain the methodological approach of understanding user requirement for tools and processes, information and guidelines for energy-efficient design, with visionary scenarios. The methodology employs narratives in a form of a scenario story. This leads to identification of the needs for tools, their features and level of interoperability for the processes, integration and collaboration.

We introduce a set of visionary scenarios developed for holistic energy-efficient design of neighbourhood and building energy systems. Two scenarios are addressed in detail: 1) collaborative planning of neighbourhood energy systems, in Ref. [9], and 2) neighbourhood energy balancing in building design. Both of them consist of visionary stories of future situations describing how new collaborative technologies, ICT services and business models could be used. The stories include the evaluation of potential impacts and the needed progress beyond the state of the art. The user requirements for the visionary stories are identified.

Presented scenarios demonstrate the usefulness of energy analysis on a higher level, beyond a single building. The practical value of utilising the district energy analysis depends strongly on how the results are communicated to the relevant stakeholders and how they are utilised in the urban planning and related decision making. The district energy analyses, when performed iteratively during the progressing planning process, reveal to urban planners the effects of their decision choices. They could also provide sufficient base information for the decision making about the land use and urban development on the city level.

The choice of metrics used in the planning process depends on the stakeholders or targeted audience. Experts and engineers are used to discussing directly about energy values (e.g. $\mathrm{MWh} / \mathrm{a}$ ) for entire districts, whereas metrics expressing values per building floor area are traditional and widely used in the building projects. Often, facility managers might be more interested about comparable metrics, such as $\mathrm{kWh} / \mathrm{m}^{2}$, a. Then, however, the effect of the size of building spaces and apartments vanishes. In practise, this could lead to a conclusion that low density apartments would have lower energy consumptions and carbon emissions, which would not necessarily support efficient space use. In public communication, indicators expressed as values per person might be easiest to understand, as giving a better perspective for public audience. And finally, instead of discussing about energy demands directly, it might be clearer for some audiences to focus on carbon emissions, or costs.

The holistic design strategy establishes a link between neighbourhood level and building level design views. This is executed firstly in the design area of building energy performance, 
and also in the local energy systems studies. Secondly, also local environmental systems of the neighbourhood are taken into account in the design area of building indoor environment performance. Thirdly, the local societal systems are integrated to design solutions configurations of alternatives in the design area of the building's usability performance.

The scenarios elaborated here are an important study topic, because new concept design tasks are needed for neighbourhood level energy-efficient design and energy matching. Currently the question is, whether it is more natural to widen the process of city planning for energy-efficient concept design, or does the design tasks have a place in the program development or in the feasibility study of the construction project. Modern model based information management provides more accurate and detailed information in an earlier phase of the process flow. This phenomenon supports the idea that a real energy-efficient concept design could be part of a real city planning or strategic program development.

These visionary scenario stories have been further utilised in the development of the D4E holistic and energy-efficient building design methodology to establish an enhanced vision of holistic design and planning, including functionalities and tools of the collaborative platform (envisioned databases, information models, decision support, interoperability and collaboration support) [13]. In the process, enchanted visions were defined of the areas of methodology, platform and created bases for envisioned business models and services.

When studying and developing methodologies for building energy design, it is necessary to anticipate also possible future changes related to energy design. We discussed changes that can be related to: operation of the building, changes in the neighbourhood energy systems, possible development of policies and legal frameworks, availability of new technologies, and other external changes in the environment.

In the future, we consider eAdaptability important for energy-efficient design and focus on solutions that are flexible towards future changes. In order to manage this type of design, a new dedicated indicator for eAdaptability should be defined.

\section{ACKNOWLEDGEMENTS}

This research is funded by the European Commission under contract FP7-2013-NMP-ENVEeB through the Design4Energy project (Grant agreement no: 609380).

\section{REFERENCES}

[1] Design4Energy project 2013-2017. Project website, accessed on 22 May, 2017. http:// www.design4energy.eu/index.html

[2] Directive 2010/31/EU of the European Parliament and of the Council of 19 May, 2010 on the energy performance of buildings. OJ L 153, 18.6.2010, pp. 13-35. Available http://data.europa.eu/eli/dir/2010/31/oj (accessed on 3 May, 2017).

[3] Hannus, M., Kazi, A.S. \& Zarli, A., ICT Supported Energy Efficiency in Construction. REEB Project Publication, 2010.

[4] Sepponen, M., Hannus, M., Hedman, Å., Tommis, M., Bourdeau, M., Decorme, R., Zarli, A., Huerva, A., Wagner, M., Blanco, A., Carlos, J., Hernandez, R., Martinez, J., Vlasveld, J., Beurden, H., Bouricius, M., Chriccio, F., Mastrodonato, C. \& Blöchle, M., D3.3.2 Roadmap for European-scale Innovation and Take-up. IREEN Project Deliverable, 2013.

[5] Ala-Juusela, M., Tracey, C. \& Hukkalainen, M., Defining and operationalising the concept of an energy positive neighbourhood. Energy Conversion and Management, 125, pp. 133-140, 2016. https://doi.org/10.1016/j.enconman.2016.05.052 
[6] CIB IDDS Core Team. CIB Priority Team: Improving Construction and Use through Integrated Design Delivery solutions (IDDS), Research Trajectories Paper, April 2012.

[7] Bassanino, M., Fernando, T., Wu, K.C., Ghazimirsaeid, G., Klobut, K., Mäkeläinen, T. \& Hukkalainen, M., A collaborative environment for energy-efficient buildings within the context of a neighborhood. Proceedings, eWork and eBusiness in Architecture, Engineering and Construction, pp. 299-307, CRC Press, 2016.

[8] Mäkeläinen, T., Hukkalainen, M., Hannus, M., Klobut, K., Shemeikka, J., Kadolsky, M., Fouchal, F., Hassan, T., Firth, S., Bassanino, M., Fernando, T., Malo, P., Pereira, P., Nguyen, V.K. \& He, X., Deliverable 2.2a Visionary Scenarios of Holistic Energy Efficiency Design. Design4Energy Project, 2017.

[9] Hukkalainen, M., Klobut, K. \& Mäkeläinen, T., Visionary scenarios for holistic planning of neighbourhood and building energy system. WIT Transactions on Ecology and the Environment. WIT Press, 224, pp. 135-146, 2017.

[10] Klobut, K., Hukkalainen, M. \& Ala-Juusela, M., New potential indicators for energy matching at neighbourhood level. Proceedings of the CIB World Building Congress, Volume I, pp. 444-455. 2016.

[11] IDEAS project (2015) Deliverables. Accessible at http://www.ideasproject.eu/IDEAS_ wordpress/deliverables/index.html

[12] Schmidt III, R., Eguchi, T., Austin, S. \& Gibb, A., What is the meaning of adaptability in the building industry? Proceedings of the CIB 16th International Conference on Open and Sustainable Building, pp. 233-242, 2010.

[13] Mäkeläinen, T., Klobut, K., Fernando, T., Hannus, M., Sepponen, M., Masior, J., Fouchal, F., Hassan, T., Firth, S. \& Bassanino, M., A new methodology for designing energy efficient buildings in neighbourhoods. Proceedings, eWork and eBusiness in Architecture, Engineering and Construction, pp. 871-878, 2014. https://doi. org/10.1201/b17396-139 